\title{
Expression of avian influenza haemagglutinin (H5) and chicken interleukin 2 (chIL-2) under control of the ptcB promoter in Lactococcus lactis
}

\author{
Katarzyna Szatraj ${ }^{* \otimes}$, Agnieszka K. Szczepankowska1*, Violetta Sączyńska², \\ Katarzyna Florys², Beata Gromadzka3 , Krzysztof Łepek³, Grażyna Płucienniczak², \\ Bogusław Szewczyk ${ }^{4}$, Włodzimierz Zagórski-Ostoja ${ }^{1}$ and Jacek Bardowski ${ }^{1}$
}

\begin{abstract}
IInstitute of Biochemistry and Biophysics, Polish Academy of Sciences, Warsaw, Poland; 2Institute of Biotechnology and Antibiotics, Department of Bioengineering, Warsaw, Poland; 3University of Gdansk and Medical University of Gdańsk, Intercollegiate Faculty of Biotechnology, Department of Recombinant Vaccines, Gdańsk, Poland; 4University of Gdańsk, Institute of Biotechnology, Department of Molecular Virology, Gdańsk, Poland
\end{abstract}

\begin{abstract}
Gram-positive and nonpathogenic lactic acid bacteria (LAB) are considered to be promising candidates for the development of new, safe systems of heterologous protein expression. Recombinant LAB has been shown to induce specific local and systemic immune response against selected pathogens, and could be a good alternative to classical attenuated carriers. The main goal of our study was to express the avian influenza haemagglutinin (H5) and chicken interleukin 2 (chlL-2) in Lactococcus lactis. Results of this study were anticipated to lead to construction of lactococcal strain(s) with potential vaccine properties against the avian influenza A (H5N1) virus. Expression of the cloned $\mathrm{H} 5$ gene, its His-tagged variant and ChIL-2 gene, under the control of the ptcB gene promoter was attested by RT-PCR on transcriptional level and Western or dot blot analysis on translational level, demonstrating that system can be an attractive solution for production of heterologous proteins. The results of the preliminary animal trial conducted in mice are a promising step toward development of a vaccine against avian bird flu using Lactococcus lactis cells as antigen carriers.
\end{abstract}

Key words: Lactococcus lactis, ptcB promoter, heterologous gene expression, avian influenza H5N1, H5 haemagglutinin, chicken interleukin-2

Received: 30 May, 2014; revised: 08 September, 2014; accepted: 10 September, 2014; available on-line: 18 September, 2014

\section{INTRODUCTION}

Lactic acid bacteria (LAB) are non-invasive and nonpathogenic Gram-positive bacteria with a GRAS (generally regarded as safe) status, widely used for food-processing and preservation. Due to their long and safe association with humans, rapid growth, small genomes and simple metabolism, LAB are considered to be promising candidates for controlled and targeted administration of vaccine antigens to the mucosal immune system (Le Loir et al., 1998; Geoffroy et al., 2000; Enouf et al., 2001; Bermudez-Humaran et al., 2002). For this, bacteria are specifically engineered to obtain recombinants, which can induce a specific local and systemic immune response against selected pathogens. The properties of many LAB include: gastric acid and bile salts tolerance, antagonistic properties against pathogenic microorganisms and ability to adhere to the gut epithelium, which makes them useful for oral immunization (Titgemeyer \& Hillen, 2002; Mota et al., 2006). Lactococcus lactis is a non-invasive and non-commensal lactic acid bacterium with low potential to trigger immunotolerance or side effects upon prolonged use (Perdigon et al., 2001). Furthermore, L. lactis elicits only a weak immune response against itself, despite its ability to act as an immunoadjuvant to accompanying antigens (Drouault et al., 1999; Guillemin et al., 2009). During the past two decades a remarkable progress has been made toward the molecular characterization of $L$. lactis and development of genetic engineering tools (Gasson \& Vos, 1994; Underdown \& Mestecky, 1994; Wood \& Warner, 2003; Wegmann et al., 2007; Wells \& Mercenier, 2008). Moreover, L. lactis has been extensively engineered for production of heterologous proteins, including some antigens of bacterial or viral origin (Sanchez et al., 2008). Promising results have been obtained for various antigens administered via different routes using $L$. lactis as a delivery vehicle (Ribeiro et al., 2002; Ramasamay et al., 2006).

The study presented here describes preliminary experiments using $L$. lactis engineered for production of the major avian influenza virus (H5N1) antigen - viral haemagglutinin (H5) and chicken interleukin 2 (chIL-2), based on the $p t c B$ promoter system. Haemagglutinin is the major protein of the influenza virus capable of inducing antibody production in the infected host. ChIL-2 is a glycoprotein produced by T-type lymphocytes under the influence of specific and nonspecific mitogens. It induces proliferation of the $\mathrm{T}$ helper and suppressor as well as cytotoxic cells and enhances the activity of NK cells. Due to such properties, it can be used in designed vaccines as a natural adjuvant (Lillehoj et al., 2001). Our study sets the basis for development of a $\mathrm{L}$. lactis strain(s) with potent vaccine properties against avian influenza A (H5N1) virus.

e-mail: szatrajka@ibb.waw.pl

*These authors contributed equally to this work

Abbreviations: $\mathrm{SLAB}$, lactic acid bacteria; $\mathrm{H} 5$, haemagglutinin of highly pathogenic $\mathrm{H} 5 \mathrm{~N} 1$ avian influenza virus; chlL-2, chicken interleukin 2; CDM, chemically defined medium; NBT/BCIP, nitro-blue tetrazolium and 5-bromo-4-chloro-3'-indolyphosphate; HPR, horseradish peroxidase; $\mathrm{CcpA}$ protein, Catabolite Control Protein $\mathrm{A}$. 


\section{MATERIALS AND METHODS}

Bacterial strains and growth conditions. Bacteria and plasmids used in this study are listed in Table 1. Bacterial cells were cultured at $30^{\circ} \mathrm{C}$ in M17 broth (Terzaghi \& Sandine, 1975) containing 0.5\% glucose (GM17) without shaking or on GM17 plates with $1.5 \%$ agar. Erythromycin (Boehringer $\mathrm{GmbH}$, Mannheim, Germany) was added to a concentration of $5 \mu \mathrm{g} \mathrm{ml}{ }^{-1}$, where necessary. For induction of protein synthesis, transformed cells were cultured overnight at $30^{\circ} \mathrm{C}$ in a chemically defined medium (CDM) containing $0.5 \%$ cellobiose and erythromycin ( $5 \mu \mathrm{g} \mathrm{ml}^{-1}$ final concentration).

DNA manipulation and transformation. The analysis was carried out by CODONW 1.4.2 (http://codonw. sourceforge.net/). Codon usage in the nucleotide sequence of both $\mathrm{H} 5$ and chIL-2 appeared to be compatible with codons preferred by L. lactis. DNA molecular cloning and restriction enzyme analysis were performed according to general procedures (Staats et al., 1994). $L$. lactis cells were made electrocompetent for transformation with the pIL253:PptcB vector or its recombinant variants as already described (Holo \& Nes, 1989; Wells et al., 1993). Plasmid DNA from L. lactis was isolated using PureYield ${ }^{\mathrm{TM}}$ plasmid mini-prep system (Promega) and a protocol modified for $L$. lactis where lysozyme was added $\left(10 \mathrm{mg} \times \mathrm{ml}^{-1}\right)$ prior to the lysis step and incubating the cell suspension for $30 \mathrm{~min}$ at $37^{\circ} \mathrm{C}$ to generate protoplasts.

Amplification of $H 5$ and $c h I L-2$ DNA genes by polymerase chain reaction (PCR). H5 [H5N1 A/ swan/Poland/305-135V08/2006 strain from AIV EpiFluDatabase [http://platform.gisaid.org]; Accession No. EP1156789], H5 with a C-terminal His-tag and cbIL-2 [GenBank AF017645] genes were amplified using a stan- dard PCR technique employing cDNA as template and specific primers listed in Table 1 .

Cloning of avian influenza virus $H 5$ and chicken $\boldsymbol{I L}$-2 genes in pIL253:PptcB vector. Recombinant plasmids were created by ligation of pIL253:PptcB vector with the 1.8-kb H5 gene PCR product or its his-tagged derivative, previously digested with BamHI/XhoI restrictases. Construct carrying additionally the chIL-2 gene downstream of the $\mathrm{H} 5$ gene was generated by digesting the 434-bp chIL-2 PCR product with BoxI and ligating it with pIL253:PptcB:H5, prepared in the same way. Recombinant constructs were selected by colony PCR, with one primer specific for the insert, and the second one specific for the plasmid sequence. Inserts in each clone were sequenced (GS FLX Titanium 454, Roche) to confirm their identity with the templates used.

Isolation of total RNA from $L$. lactis. RNA samples were isolated from logarithmic-phase $L$. lactis cultures grown on CDM medium supplemented with $0.5 \%$ cellobiose using commercial RNeasy mini Kit (Qiagen). RNA samples were stored at $-80^{\circ} \mathrm{C}$ prior to further use.

Reverse transcription analysis. Reverse transcription (RT) reaction was performed with the SuperScript ${ }^{\mathrm{TM}}$ III reverse transcriptase kit (Invitrogen), according to the manufacturer's instructions, using an appropriate reverse primer (Table 1). Specific cDNA was amplified using a standard PCR technique and a pair of specific primers (Table 1).

Protein isolation. Recombinant strains harboring H5and chIL-2-coding genes were grown in CDM medium, to an optical density $\mathrm{OD}_{600}$ equal 0.6. Crude extracts were obtained by disrupting the cells at high speed using the Mini Bead Beater (MBB-8) device and glass beads (106- $\mu \mathrm{m}$ diameter; Sigma) $3 \times$ for $1 \mathrm{~min}$ with 1 -min intervals, during which the cells were kept on ice. Cellular

Table 1. Bacterial strain, plasmids and primers used in this study.

\begin{tabular}{|c|c|c|}
\hline Bacterial strain & Properties & reference \\
\hline IL1403 & Laboratory, wild type, plasmid-free strain & (Chopin et al, 1984) \\
\hline Plasmids & Properties & reference \\
\hline plL253:PptcB & $\mathrm{Em}^{\mathrm{R}}$, plL253-derivative with $p t c B$ gene promoter region & IBB PAS collection \\
\hline plL253:PptcB:H5 & $\begin{array}{l}\text { Em }{ }^{\mathrm{R}} \text {, plL253-derivative with } p t c B \text { gene promoter region, enco- } \\
\text { ding } H 5 \text { gene of } \mathrm{H} 5 \mathrm{~N} 1\end{array}$ & this work \\
\hline plL253:PptcB:H5His & $\begin{array}{l}\text { Em }{ }^{\mathrm{R}} \text {, plL253-derivative with ptcB gene promoter region enco- } \\
\text { ding } \mathrm{H} 5 \text { gene of H5N1 fused with His-tag nucleotide sequence } \\
\text { at } \mathrm{C}^{\prime} \text { terminal end }\end{array}$ & this work \\
\hline plL253:PptcB:H5:chIL2 & $\begin{array}{l}\text { Em }{ }^{\mathrm{R}} \text {, plL253-derivative with } p t c B \text { gene promoter region enco- } \\
\text { ding } H 5 \text { gene of } \mathrm{H} 5 \mathrm{~N} 1 \text { and chlL2 }\end{array}$ & this work \\
\hline Primer & Nucleotide sequence & \\
\hline HAF & $\begin{array}{l}\text { 5'CGGGATCCCGAAGGAGTATTTCTATGGA } \\
\text { GAATATAGTGCTTCTIT3' }\end{array}$ & \\
\hline HAR & 5'CCGCTCGAGTTAAATGCAAATTCT3' & \\
\hline HAHisR & $\begin{array}{l}\text { 5'CCGCTCGAGTTATTAATGATGATGATGAT } \\
\text { GATGAATGCAAATTCTGCGTTG3' }\end{array}$ & \\
\hline chIL-2F & $\begin{array}{l}\text { 5'GCGACGAGCGTCAAAAGGAGGTATTTCTA } \\
\text { TGATGTGCAAATGA3' }\end{array}$ & \\
\hline ChIL-2R & 5'CGGACGAGCGTCGCGACCGGTITATTATITTGCAG3' & \\
\hline
\end{tabular}

*Conditions for DNA amplification were determined depending on each primer and length of the amplified sequence. Sequences recognized by particular restriction enzymes are shown in bold. 
debris and glass beads were removed by centrifugation for $10 \mathrm{~min}$ at $8000 \mathrm{rpm}$. Protein concentrations were determined using Nano Drop (Thermo Scientific).

SDS/PAGE analysis of protein extracts. Equal volumes of $2 \times$ loading buffer $(125 \mathrm{mM}$ Tris/ $\mathrm{HCl} \mathrm{pH}$ 6.8, 4\% SDS, $10 \% \quad \beta$-mercaptoethanol, $20 \%$ glycerol, and $0.01 \%$ bromophenol blue) and protein extracts were combined. Subsequently, samples were incubated for 5 $\mathrm{min}$ at $95^{\circ} \mathrm{C}$ and then cooled on ice for $5 \mathrm{~min}$. Next, protein samples were analyzed by SDS/PAGE (110 V, $500 \mathrm{~mA}, 2 \mathrm{~h}$ ). Inclusion bodies obtained by over-expression of H5-coding gene in E. coli were used as a positive control for protein analysis. Negative standard protein samples obtained from IL1403 [pIL253:PptcB] were used for data normalization.

Western-blot analysis for $\mathbf{H} \mathbf{5}$ antigen. Proteins separated by SDS/PAGE were transferred onto nitrocellulose Hybond-C Extra membranes (Amersham) at $45 \mathrm{~A}$ and constant $\mathrm{V}$ for $1 \mathrm{~h}$ using semi-dry blotter (Hoefer). Membranes were blocked overnight at $4^{\circ} \mathrm{C}$ with TS buffer (20 mM Tris, $0.13 \mathrm{mM} \mathrm{NaCl}$, pH 8.0), containing $3 \%$ skim milk. Immunoblotting was carried out using commercial monoclonal mouse antibodies against the $\mathrm{H} 5$ antigen (Abcam), diluted at 1:1000.

Immunodetection was performed with secondary rabbit or mouse antibodies conjugated with alkaline phosphatase (Sigma) at dilution 1:30000 and NBT/BCIP Stock Solution (Roche) as above.

Dot blot detection of chIL2. Five $\mu$ l of total protein extracts were deposited on a Hybond- C Extra nitrocellulose membrane (Amersham). The dot-blot membrane was air-dried for $5 \mathrm{~min}$, blocked at $37^{\circ} \mathrm{C}$ for $20 \mathrm{~min}$ in TS buffer $(20 \mathrm{mM}$ Tris, $0.13 \mathrm{mM} \mathrm{NaCl}, \mathrm{pH} 8.0)$ containing 3\% skim milk, and then incubated with chIL-2-specific commercial monoclonal antibodies (AbDserotec), at dilution 1:1000. Immunodetection was performed with secondary mouse antibodies conjugated with alkaline phosphatase (Sigma) at dilution 1:30000 and NBT/BCIP Stock Solution (Roche) as recommended by the suppliers. Negative standard protein samples obtained from IL1403 [pIL253:PptcB) were used for data normalization. Recombinant chicken interleukin-2 (PAP005 AbDSerotec) served as a positive control.

Mouse immunization and sample collection. All work was performed ethically in compliance with the First Warsaw Local Ethics Committee for Animal Experimentation. Ten-week-old female BALB/c mice (Mossakowski Medical Research Centre of Polish Academy of Sciences, Warsaw, Poland), counting four groups of 5 mice each, were immunized intragastrically (i.g.) with $10^{9} \mathrm{CFU}$ of recombinant $L$. lactis expressing a single $\mathrm{H} 5$ antigen (group 1), both $\mathrm{H} 5$ and chIL-2 proteins (group 2), with bacterial protein extract from IL1403 [pIL253:PptcB:H5] (group 3), and with L. lactis carrying the empty vector [pIL253:PptcB] — control group. Same doses were administered to animals for the first three days of the trial, and then four times at 1-week intervals. Blood samples from the orbital sinus were collected four days after first three doses, six days after each subsequent booster, and 7 and 14 days after the last immunization. To obtain serum, whole blood samples were left to coagulate at room temperature for approximately 15 to 30 minutes. The clot was rimmed using an applicator stick and then the sample was centrifuged twice at $4^{\circ} \mathrm{C}$ for approximately $10 \mathrm{~min}$ at $10000 \mathrm{~g}$. Obtained serum samples were stored at $-80^{\circ} \mathrm{C}$ until assayed.

Enzyme-linked immunosorbent assay (ELISA). Collected sera $(15 \mu \mathrm{l})$ were assayed for the presence of antibodies against $\mathrm{H} 5$ antigen by an ELISA method, using MaxiSorp plates (Nunc) coated with mammalian cell-expressed $\mathrm{H} 5$ protein $(17-530$ aa, $\triangle \mathrm{RRRKKR})$ of A/Bar-headed Goose/Qinghai/12/05 (H5N1)) strain of influenza A virus $\left(3 \mu \mathrm{g} \times \mathrm{ml}^{-1}\right.$ ) (Immune Technology). Secondary labeling and its detection were done with reagents purchased from Sigma-Aldrich. Serum samples from i.g. immunized mice with $\mathrm{H} 5$ harbored by $L$. lactis were tested in parallel with serum from sham-immunized mice (negative controls). Monoclonal antibodies to avian influenza A virus (H5N1) HA (US Biological, Acris Antibodies) were used as positive controls. Experimental samples, diluted 1:25 in 2\% BSA-PBS, positive controls and blanks (sample diluent) were applied onto the plates previously coated with $\mathrm{H} 5\left(3 \mu \mathrm{g} \times \mathrm{ml}^{-1}\right.$ in PBS, overnight, $2-8^{\circ} \mathrm{C}$ ) and then incubated overnight at $2-8^{\circ} \mathrm{C}$. Antibody classes were detected with goat generated and horseradish peroxidase (HRP)-labeled antibodies against mouse $\operatorname{IgG}(\gamma$-chain specific) and $\operatorname{IgA}(\alpha$-chain specific) at $1: 500$ dilution $\left(1 \mathrm{~h}, 37^{\circ} \mathrm{C}\right)$. In all tests performed, TMB was used as the substrate. After incubation for 30 min at room temperature, the reaction was stopped by the addition of $0.5 \mathrm{M}$ sulfuric acid. The absorbance was quantified at $450 \mathrm{~nm}$ with subtraction of the mean OD readings of blanks. Samples were considered to be positive for anti-H5 antibodies if the OD readings were 2SD above the mean OD readings of samples from control mice (cut-off value).

\section{RESULTS}

\section{Recombinant $\mathrm{H} 5$ and chIL-2 expression in L. lactis}

Expression of H5, H5 His-tag and chIL-2 genes under the control of the $p t c B$ promoter was attested by RT-PCR. The main products of $1.8 \mathrm{~kb}$ and $434 \mathrm{bp}$ corresponding respectively to $\mathrm{H} 5$ - and chIL-2-encoding regions were identified (data not shown). No positive signals were noted for the negative control. Subsequently, specific positive signals on the translational level were detected in immunoenzyme reactions. However, Western blot analysis performed for the $\mathrm{H} 5$ protein revealed intracellular proteolysis of the antigen, visible as a ladder on the nitrocellulose membrane. This degradation was also visible and confirmed for the His-tagged protein

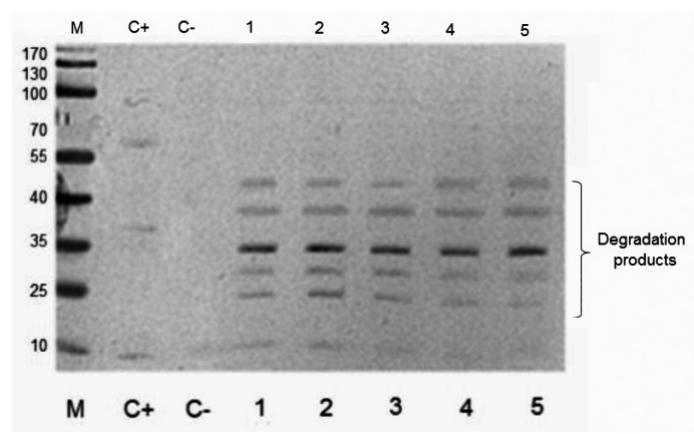

Figure 1.Western blot analysis of $\mathrm{H} 5$ production under $p t c B$ promoter with anti-His commercial antibodies.

Immunoblotting was carried out using $\mathrm{H} 5$ specific commercial monoclonal mouse antibodies (Abcam) diluted at 1:1000. Immunodetection was performed with secondary mouse antibodies conjugated with alkaline phosphatase (Sigma) at dilution 1:30000 and a NBT/BCIP Stock Solution (Roche) as recommended by the suppliers. Intracellular proteolysis of the antigen was visible as a characteristic ladder of bands on the nitrocellulose membrane (lanes 1, 2, 3, 4, 5 - protein extracts of IL1403 [pll253:PptcB:H5His] strain). No specific products were observed for negative control - protein extract of IL1403 [pll253:PptcB] (C-). 


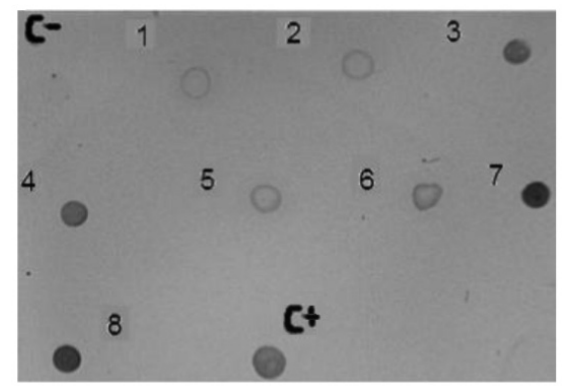

Figure 2.Dot blot analysis for chIL-2 production in the IL1403 [pIL253:PptcB:H5:IL-2] strain.

The dot-blot membrane was air-dried for $5 \mathrm{~min}$, blocked with $10 \%$ nonfat dry milk blocking buffer at $37^{\circ} \mathrm{C}$ for $20 \mathrm{~min}$, and then incubated with the primary antibody using a chIL-2 specific commercial monoclonal antibodies (AbDserotec), at dilution 1:1000, and with secondary mouse antibodies conjugated with alkaline phosphatase (Sigma) at dilution 1:30000. Immunodetection was performed with NBT/BCIP Stock Solution (Roche) as recommended by the suppliers. Negative standard protein samples IL1403 [plL253:PptcB] were used for data normalization. C- (negative control), 1-2 and 5-6 soluble fraction; 3-4 and 7-8 insoluble, membrane fraction, $\mathrm{C}+$ (positive control).

(Fig. 1). For the chIL-2 protein (Fig. 2), both the soluble and insoluble fraction samples gave positive signals, with a definitely stronger signal for samples enriched with the membrane fraction. The negative control did not react with the antibody.

\section{ELISA detection of H5-specific serum antibody}

Immunogenicity of $L$. lactis-expressed H5 antigen was investigated in the mouse model. Recombinant bacteria in the form of live vector vaccine or protein extracts were administered by intragastric gavage using the same time scheme. In mice immunized with $L$. lactis expressing the $\mathrm{H} 5$ antigen alone (group 1), only weak serum $\operatorname{IgG}$ and $\mathrm{IgA}$ responses were observed (Fig. 3A and B). Only a single mouse responded slightly stronger with an $\mathrm{IgG}$ peak after administration of the third dose (Fig. 3A). Higher serum antibody responses were shown for mice in group 2, vaccinated with $L$. lactis co-expressing $\mathrm{H} 5$ and chIL-2. Antigen-specific IgG antibodies were detected in serums collected after the third and subsequent immunizations (Fig. 4A) and for IgA isotype at different time points of the experiment (Fig. 4B). Three out of four mice in group 2 responded more effectively with serum IgG after the fourth booster (Fig. 4A). For two mice this was accompanied by increased IgA levels (Fig. 4B). The strongest response was induced using the protein extract from H5-producing L. lactis (group 3), yet, this effect was observed for only one out of four mice. In this case, $\operatorname{IgG}$ antibodies against $\mathrm{H} 5$ were detected in the serum after the fourth immunization and peaked 7 days after application of the fifth dose (Fig. 5A and B). This was not accompanied by $\operatorname{IgA}$ response. The remaining mice from group 3 did not develop anti-H5 antibodies. Samples from mice sham-immunized with the control strain gave low OD values, which were constant during the whole experiment. This is indicated in the figures as dashed cut-off lines. In summary, four mice developed more pronounced $\mathrm{H} 5$-specific IgG antibodies in sera after three-four boosters of recombinant $L$. lactis expressing H5 (Fig. 3A and Fig. 4A).

\section{DISCUSSION}

In this study, a new system of protein production in L. lactis has been tested. The idea was based on carbon catabolite repression operating in Gram-positive bacteria that is exerted through binding of the CcpA protein to cre, a cis-acting catabolite responsive element (Aleksandrzak-Piekarczyk et al., 2005). CcpA can act as an activator of the promoter sequence of the regulated gene or an inhibitor. The promoter sequence of the chromosomal $L$. lactis $p t c B$ gene, containing a cre sequence, was used to create the pIL253:P $p t c B$ vector to potentially increase heterologous protein production in transformed $L$. lactis strains. The activity and efficiency of the $p t c B$ promoter region was already described by Aleksandrzak-Piekarczyk et al., 2011. To investigate the efficiency in immunoprotection against avian influenza virus, three $L$. lactis strains expressing genes for avian influenza virus $\mathrm{H} 5$ protein and chicken IL-2 from the pIL253:P ptcB vector were analyzed. For this, recombinant bacteria in the form of live vector vaccine or protein extract were administered to $\mathrm{BALB} / \mathrm{c}$ mice by intragastric gavage using the same time scheme. Serum antibody responses of $\operatorname{IgG}$ and $\operatorname{IgA}$ isotypes were monitored. These antibodies are considered to be one of the most effective de-
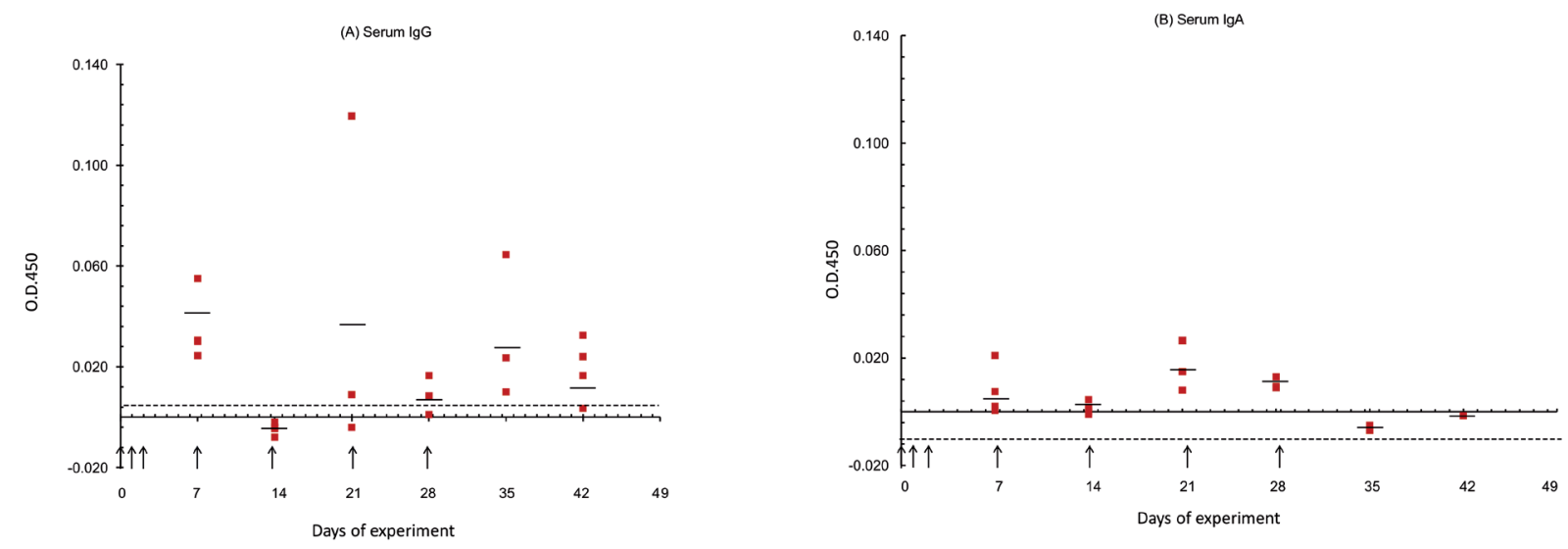

Figure 3. Serum antibody response after immunization with $L$. lactis expressing $\mathrm{H} 5$ antigen.

Five mice were immunized seven times with $10^{9}$ CFU of L. lactis [plL253:PptcB:H5] on days indicated by arrows. Serum samples were collected at various time points of the experiment. Levels of H5-specific $\operatorname{lgG}(\mathbf{A})$ and $\lg$ A (B) antibodies were determined in samples diluted 1:25. Results obtained for immunized mice at each time point of blood sampling are shown individually (squares) and as mean OD values (dashes). The mean OD readings higher by 2 SD than control mice samples were considered as the cut-off indicated by the dashed line. 

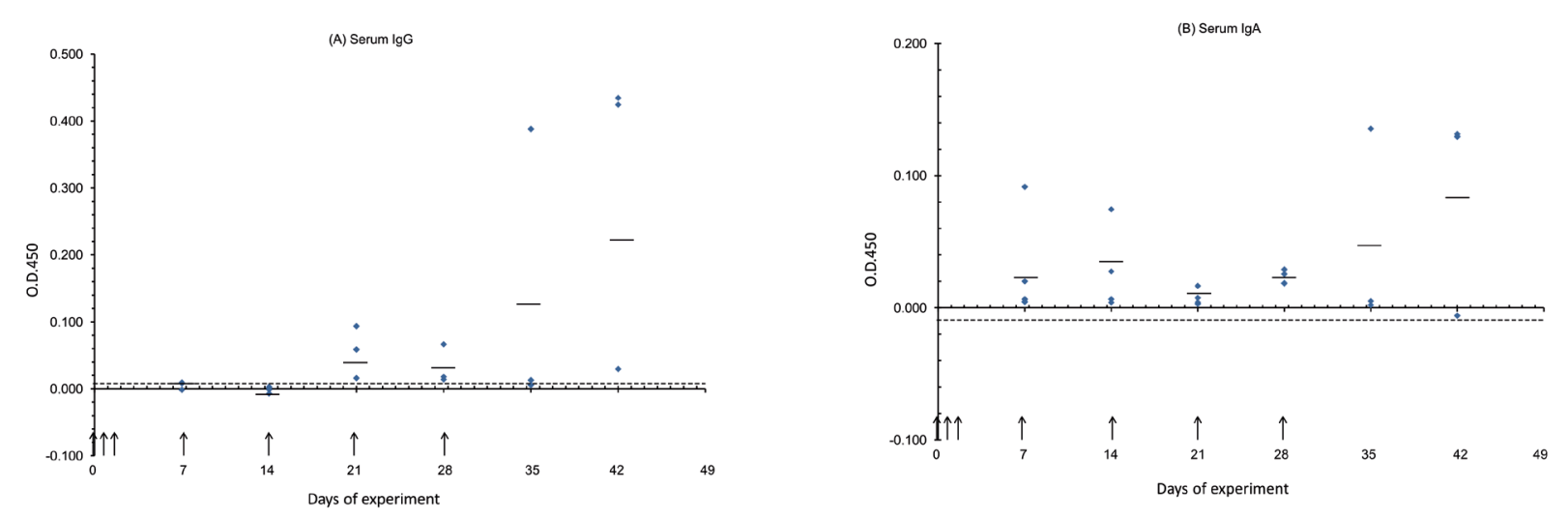

Figure 4. Serum antibody response after immunization with L. lactis expressing $\mathrm{H} 5$ and chIL-2.

Five mice were immunized seven times with $10^{\circ}$ CFU of L. lactis [pIL253:PptcB:H5:IL-2] on days indicated by arrows. Serum samples were collected at various time points of the experiment. Levels of H5-specific $\lg G(\mathbf{A})$ and $\lg$ A (B) antibodies were determined in samples diluted 1:25. Results obtained for immunized mice at each time point of blood sampling are shown individually (diamonds) and as mean $\mathrm{OD}$ values (dashes). The mean OD readings higher by 2 SD than control mice samples were considered as the cut-off indicated by the dashed line.
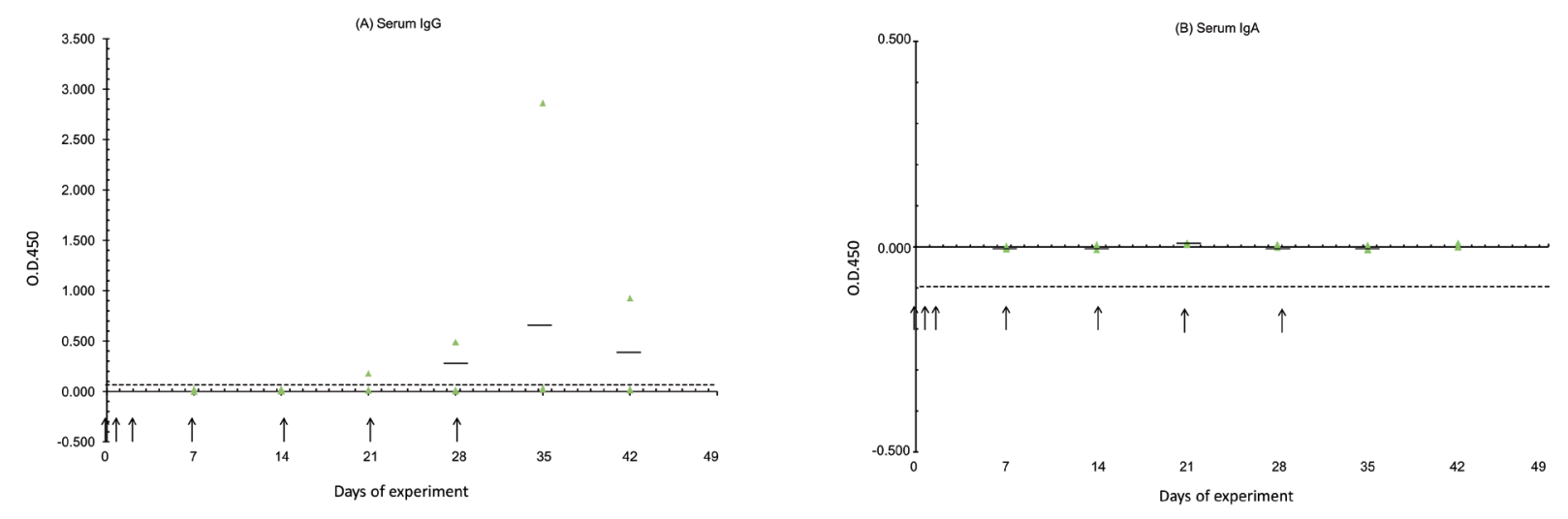

Figure 5. Serum antibody response after immunization with protein extract from L. lactis expressing H5.

Five mice were immunized seven times on days indicated by arrows with protein extract obtained from IL1403 [pIL253:PptcB:H5] corresponding to $10^{9} \mathrm{CFU}$. Serum samples were collected at various time points of the experiment. Levels of H5-specific $\operatorname{lgG}$ (A) and IgA (B) antibodies were determined in samples diluted 1:25. Results obtained for immunized mice at each time point of blood sampling are shown individually (triangles) and as mean OD values (dashes). The mean OD readings higher by 2 SD than control mice samples were considered as the cut-off indicated by the dashed line.

fense mechanisms against respiratory infections and a vital attribute of any vaccine designed to prevent infections (Lamm, 1997; Xi net al., 2003). Preliminary animal trial showed the capability of recombinant L. lactis strains producing the $\mathrm{H} 5$ antigen to evoke an immune response via the mucosal route. Moreover, antibodies induced with $L$. lactis-expressed H5 recognize recombinant $\mathrm{H} 5$ of mammalian-cell origin, which has been shown to preserve essential epitopes of the native protein and its oligomeric structure (data not shown). The best immunization results were obtained with the use of a strain co-expressing H5 and chIL-2, as mice from this group gave the clearest response to vaccination as judged by $\operatorname{IgG}$ and $\mathrm{IgA}$ level of anti-H5 antibodies (Fig. $4 \mathrm{~A}$ and B). Overall, the enhanced immune response observed in this animal group was presumably related to the presence of chIL-2, anticipated to play a role of an adjuvant. In particular, chIL-2 has been studied widely as an immuno-enhancer due to its role in activating $\mathrm{T}$ cell proliferation. The unsatisfactory number of responder mice and overall low levels of serum $\mathrm{H} 5$-specific antibodies were probably, and at least partially, due to the low amounts of properly folded H5, caused by strong intracellular proteolysis of expressed antigen inside bacterial cells. The proteolytic pattern of degradation observed for the heterologous protein is far different from that which occurs during a natural viral infection of host cells. Such effect often leads to production of many undesirable epitopes which can be a response-limiting factor. On the other hand, strong serum antibody response is difficult to induce solely by the mucosal route and several experiments are often needed to establish an effective immunization scheme.

In summary, our group demonstrated here the use of $L$. lactis as a biological host for production of viral antigen and chicken cytokine. The tested $p t c B$ promoter region might be an attractive system for production of heterologous proteins. The results of the preliminary animal trial conducted in mice are a promising step toward development of a vaccine against avian bird flu using L. lactis cells as antigen carriers.

\section{Competing interests}

The authors declare that they have no competing interests. 


\section{Acknowledgements}

We are indebted to Prof. Agnieszka Sirko (Institute of Biochemistry and Biophysics, Polish Academy of Sciences, Warsaw, Poland) for a gift of cDNA with chIL-2 gene, and to Małgorzata Kęsik and Agnieszka Romanik (Institute of Biotechnology and Antibiotics, Warsaw, Poland) for HA antigen produced in E. coli, used as a positive control for H5 in Western blot.

This work was funded by European Funds Portal Innovative Economy "Centre of medicinal product biotechnology. Package of innovative biopharmaceuticals for human and animal therapy and prophylactics." POIG.01.01.02.-14-007/08-06.

\section{REFERENCES}

Aleksandrzak-Piekarczyk T, Kok J, Renault P, Bardowski J (2005) Alternative lactose catabolic pathway in Lactococcus lactis IL1403. Appl Environ Microbiol 71: 6060-6069.

Aleksandrzak-Piekarczyk T, Polak J, Jezierska B, Renault P, Bardowski J (2011) Genetic characterization of the CcpA-dependent, cellobiose-specific PTS system comprising CelB, PtcB and PtcA that transports lactose in Lactococcus lactis IL1403. Int J Food Microbiol 145: 186-194.

Bermúdez-Humarán LG, Langella P, Miyoshi A, Gruss A, Tamez Guerra R, Montes de Oca-Luna R, Le Loir Y (2002) Production of Human Papillomavirus Type 16 E7 Protein in Lactococcus lactis. Appl Environ Microbiol 68: 917-922.

Chopin A, Chopin MC, Moillo-Batt A, Langella P (1984) Two plasmid determined restriction and modification systems in Streptococcus lactis. Plasmid 11: 260-263.

Drouault S, Corthier G, Ehrlich SD, Renault P (1999) Survival, physiology, and lysis of Lactococcus lactis in the digestive tract. Appl Environ Microbiol 65: 4881-4886.

Enouf V, Langella P, Commissaire J, Cohen J, Corthier G (2001) Bovine rotavirus nonstructural protein 4 produced by Lactococcus lactis is antigenic and immunogenic. Appl Environ Microbiol 67: 1423-1428.

Gasson MJ, de Vos WM. (1994) Genetics and biotechnology of lactic acid bacteria. Blackie Academic and Professional, Glasgow.

Geoffroy MC, Guyard C, Quatannens B, Pavan S, Lange M, Mercenier A (2000) Use of green fluorescent protein to tag lactic acid bacterium strains under development as live vaccine vectors. Appl Environ Microbiol 66: 383-391.

Guillemin N, Meunier B, Jurie C, Cassar-Malek I, Hocoquette JF, Leveziel H, Picard B (2009) Validation of a dot-blot quantitative technique for large scale analysis of beef tenderness biomarkers. J Physiol Pharmacol 60: 91-97.

Holo $\mathrm{H}$ and Nes IF (1989) High-frequency transformation, by electroporation, of Lactococcus lactis subsp. cremoris grown with glycine in osmotically stabilized media. Appl Environ Microbiol 55: 3119-3123.

Lamm ME (1997) Interaction of antigens and antibodies at mucosal surfaces. Annu Rev Microbiol 51: 311-340.
Le Loir Y, Gruss A, Ehrlich SD, Langella P (1998) A nine-residue synthetic propeptide enhances secretion efficiency of heterologous proteins in Lactococcus lactis. J Bacteriol 180: 1895-1903.

Lillehoj HS, Min W, Choi KD, Babu US, Burnside J, Miyamoto T, Rosenthal BM, Lillehoj LP (2001) Vet Immunol Immunopathol 82: 229-244.

Mota RM, Moreira JLS, Souza MR, Fátima Horta M, Teixeira SMR, Neumann E, Nicoli JR, Nunes AC (2006) Genetic transformation of novel isolates of chicken Lactobacillus bearing probiotic features for expression of heterologous proteins: a tool to develop live oral vaccines. BMC Biotechnology 6: 2.

Perdigon G, Fuller R, Raya R (2001) Lactic acid bacteria and their effect on the immune system. Curr Issues Intest Microbiol 2: 27-42.

Ramasamay R, Yasawardena S, Zomer A, Venema G, Kok J, Leenhouts K (2006) Immunogenicity of a malaria parasite antigen displayed by Lactococcus lactis in oral immunisations. Vaccine 24: 39003908.

Ribeiro LA, Azevedo V, Le Loir Y, Oliveira SC, Dieye Y, Piard JC, Gruss A, Langella P (2002) Production and targeting of the Brucella abortus antigen L7/L12 in Lactococcus lactis: a first step towards food-grade live vaccines against brucellosis. Appl Environ Microbiol 68: 910-916.

Sánchez J, Borrero J, Gómez-Sala B, Basanta A, Herranz C, Cintas LM, Hernández PE (2008) Cloning and heterologous production of hiracin JM79, a Sec-dependent bacteriocin produced by Enterococcus birae DCH5, in lactic acid bacteria and Pichia pastoris. Appl Environ Microbiol 74: 2471-2479.

Staats HF, Jackson RJ, Marinaro M, Takahashi I, Kiyono H, McGhee JR (1994) Mucosal immunity to infection with implications for vaccine development. Curr Opin Immunol 6: 572-583.

Terzaghi E, Sandine WE (1975) Improved medium for lactic streptococci and their bacteriophages. Appl Environ Microbiol 29: 807-813.

Titgemeyer F, Hillen W (2002) Global control of sugar metabolism: a gram-positive solution. Antonie V an Leeuwenhoek 82: 59-71.

Underdown BJ, Mestecky J (1994) Mucosal Immunoglobulin. In Handbook of Mucosal Immunology, Ogra P, Mesteck J, Lamm ME, Strober W, McGhee JR, eds, pp 79-98. Academic Press, Boston, MA.

Wegmann U, O'Connell-Motherway M, Zomer A, Buist G, Shearman C, Canchaya C, Ventura M, Goesmann A, Gasson MJ, Kuipers OP, van Sinderen D, Kok J (2007) Complete genome sequence of the prototype lactic acid bacterium Lactococcus lactis subsp. cremoris MG1363. I Bacteriol 189: 3256-3270.

Wells JM, Wilson PW, Norton PM, Gasson JM, Le Page RW (1993) Lactococcus lactis: high-level expression of tetanus toxin fragment C and protection against lethal challenge. Mol Microbiol 8: 1155-1162.

Wells JM, Mercenier A (2008) Mucosal delivery of therapeutic and prophylactic molecules using lactic acid bacteria. Nat Rev Microbiol 6: 349-362.

Wood BJB, Warner PJ (2003) Genetics of lactic acid bacteria. New York: Kluwer Academic/Plenum.

Xin KQ, Hoshino Y, Toda Y, Igimi S, Kojima Y, Jounai N, Ohba K, Kushiro A, Kiwaki M, Hamajima K, Klinman D, Okuda K (2003) Immunogenicity and protective efficacy of orally administered recombinant Lactococcus lactis expressing surface-bound HIV. Env Blood 102: 223-228. 